\title{
Japanese court backs woman researcher
}

Robert Triendl, Tokyo

For what is believed to be the first time, charges of sex discrimination against a professor in a public university have been upheld by a Japanese district court.

In a recent ruling, the government of Japan's Nara prefecture has been ordered to pay $¥ 550,000$ (US\$5,000) in compensation to Kumiko Ogoshi, an associate professor in the department of public health at Nara Medical University.

In addition to some minor charges, such as the disposal of liquid waste in the plaintiff's office, the professor supervising Ogoshi was found guilty of "unjust distribution of research funds", "refusals to sign necessary documents", and "attempts to urge Ogoshi to resign or transfer".

But, referring to a legal exemption for government officials acting on duty, the court said that the compensation should be paid by Nara's prefectural government, rather than by the academic himself.

Three years ago, after more than two decades as an assistant professor, Ogoshi decided to sue her supervising professor on the grounds of unfair treatment and "bullying". She says that she took this action only when the situation became "unbearable" after she launched an association of assistant professors in 1993, which drew attention to problems in Japan's academic research system. "I simply couldn't continue doing my research work any more," she says.

Many female scientists in Japan say they have been exposed to similar pressures. The percentage of female scientists in career positions is very small.

Only 7\% of professors in Japan's public universities are female. And as most of these are concentrated in disciplines such as household economics or literature, the number in science and engineering departments is considerably lower.

This is in sharp contrast to an increasing number of female science graduates in the country - and a comparable increase in co-authorship by female scientists of highly cited papers. But, in a system where hiring and promotion decisions often depend heavily on personal contacts or recommendations from a senior professor, female scientists face significant career barriers.

A researcher at a national research laboratory who prefers to remain anonymous says her promotion to group leader was evaluated negatively on the grounds of a lack of management experience. "But in reality, they just didn't want to have a woman at laboratory-chief meetings," she says.

In one high-profile case, Akiko Itai, an assistant professor in the pharmaceutical department at the University of Tokyo, decided to set up her own company after the university repeatedly refused to promote her to professor. Today she runs the Institute of Medicinal Molecule Design, a rational drug-design company and one of Japan's most successful new biotechnology ventures.

Ogoshi says she is pleased by the court's decision to award her compensation, but adds that the courts have shown "little understanding" for the situation in Japanese universities where an organizational model called the ' $k o z a$ system' gives professors almost unlimited control over their juniors.

Although Ogoshi says she does not expect the situation in Japanese universities to change soon, she argues that changes will never arrive "if women scientists don't speak out".

http://www.sorifu.go.jp/danjyo/index2.html

\section{Singapore to create nationwide disease database}

David Cyranoski, Tokyo

Singapore's genetic diversity is set to come under scrutiny with the creation of a nationwide disease database. Containing both clinical records and genetic information, the project is the first major goal of the national genomics programme launched earlier this year.

The database is likely to combine personal data - such as medical history and family pedigree - with tissue, body fluid and DNA samples. Initially, it will cover patients suffering from common conditions such as cancer, heart disease, stroke and myopia. In the long term, the database will probably expand to cover health-related information on the general population.

The Singapore Genomics Programme (SGP) was set up in June with funding of S\$62 million (US\$35 million) over five years. Its original remit was to focus on novel genes and their related molecular targets in an effort to diagnose and treat diseases, such as liver cancer, that have a relatively high incidence in Singapore and Asia.

The idea of creating a broad-ranging database, rather than just focusing on a few specific diseases, is based on suggestions by the International Advisory Council (IAC),

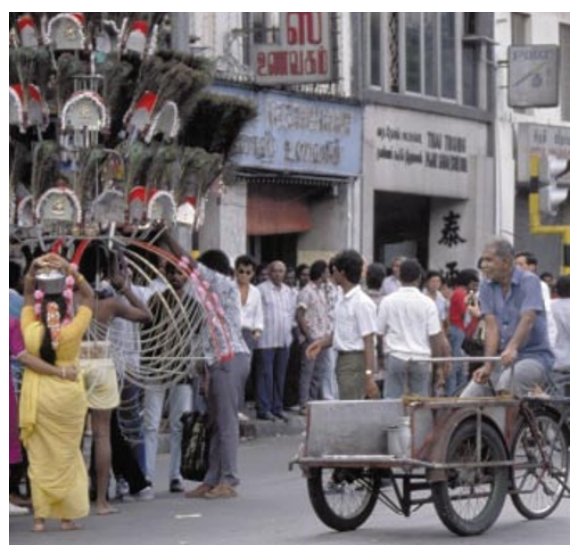

Melting pot: Singapore's people are a mixture of Chinese, Malaysians and Indians.

which advises Singapore on life sciences. The council suggested that the SGP should take advantage of Singapore's unique diversity to establish a fundamental scientific resource.

Singapore's remarkably stable racial mix, featuring a large number of Indians and Malaysians as well as the Chinese majority, offers unique advantages compared with the homogeneity of other countries such as Iceland and Estonia. For example, researchers

$\approx \odot 2000$ Macmillan Magazines Ltd will be able to follow the responses of different races to a given drug.

According to its director, Kong Hwai Loong, the SGP will now concentrate on building up the databases, manpower and core technologies — including microarrays and high-throughput sequencers - that will be needed for the broader study.

Based on another IAC recommendation, the SGP also plans to make its data freely available to all academic research institutes in Singapore. Kong acknowledges that many ethical issues, including informed consent and protection of privacy, need to be addressed. He notes that this will be especially important when the study is expanded to collect DNA and other samples from the 'normal' population — those who appear free of disease.

Much like the genetic study underway in Iceland, Kong anticipates that it will take a couple of years to sort out the ethical aspects of such a study. Although the SGP is not planning to examine a "major chunk of the population" as in Iceland, Kong acknowledges that study of the 'normal' population is inevitable. "It is just a matter of what level of sophistication we will be able to achieve," he says. 